\title{
Estimados Colegas Neurocirujanos de Chile
}

Como ya es sabido, durante los próximos años Chile se prepara para transitar de país emergente a un país desarrollado, lo cual conlleva una serie de ajustes y cambios de la cultura de trabajo, en las distintas áreas de la sociedad. Esto nos obliga como médicos y como especialistas, a evaluar cuál es nuestro rol y cómo nos adaptamos a los múltiples cambios. Entre ellos están los avances tecnológicos tanto en la información y su manejo como en el desarrollo de nuevas herramientas diagnósticas y terapéuticas, lo cual ha contribuido a incrementar significativamente la velocidad de la generación del conocimiento científico. También se han producido cambios de los establecimientos de salud, introduciendo medición de gestión, calidad y acreditación permanentes, lo cual nos obliga a aprender y desarrollar también tareas administrativas. Paralelamente la sociedad global se ha hecho más demandante y con altas expectativas, enfrentándonos a lo que se conoce como derechos y deberes del paciente, careciendo de un modelo de protección a la figura del médico. Todo lo anterior constituye un gran desafío, que nuestra Sociedad de Neurocirugía de Chile entiende y adopta, intentando mantener un trabajo continuo en una de las especialidades más complejas y con mayor potencial de crecimiento.

En este contexto, durante mi presidencia de la Sociedad de Neurocirugía de Chile, mantendremos algunos propósitos transversales. Será una sociedad integradora, inclusiva, que propicie el nuevo conocimiento, que apoye el uso racional de las tecnologías, que haga uso de todos los medios para la educación médica de la especialidad, como la página Web, la revista, como órgano oficial de nuestra sociedad con intención de indexación futura, educación médica continua para socios, foros por subespecialidad en internet, intercambios de becarios entre las distintas facultades y países, entre otros. También, otro objetivo fundamental es aumentar el número de socios, que es el capital que nutre de conocimiento e ideas y contribuye a una mayor representatividad y mejor proyección de nuestra sociedad. Para todas estas tareas, requerimos el entusiasmo y apoyo de todos los neurocirujanos del país, los más antiguos con sus conocimientos y sabiduría, como también los más jóvenes con sus talentos y energía para enfrentar nuevos desafíos. Creemos firmemente que esta simbiosis es indispensable para apoyar y fortalecer tanto la actividad neuroquirúrgica de Chile como a cada uno de los integrantes de nuestra Sociedad.

Dr. Carlos Guzmán Kramm Presidente Sociedad Chilena de Neurocirugía 